\title{
Research on Improved Deadbeat Control Strategy Based on Interpolation Prediction and Online Inductance Identification
}

\author{
Zhihe Fu $\mathbb{D}^{1},{ }^{1}$ Huangsheng Xie, ${ }^{1}$ Jiaxiang Xue $\mathbb{D}^{2},{ }^{2}$ Haisong Luo, ${ }^{2}$ and Zhuangbin Lin $^{2}$ \\ ${ }^{1}$ Department of Mechanical and Electrical Engineering, Longyan University, Longyan 364012, China \\ ${ }^{2}$ School of Mechanical and Automotive Engineering, South China University of Technology, Guangzhou 510640, China \\ Correspondence should be addressed to Zhihe Fu; fuzhihe@lyun.edu.cn
}

Received 6 March 2019; Revised 15 November 2019; Accepted 2 December 2019; Published 21 January 2020

Academic Editor: James Lam

Copyright (c) 2020 Zhihe Fu et al. This is an open access article distributed under the Creative Commons Attribution License, which permits unrestricted use, distribution, and reproduction in any medium, provided the original work is properly cited.

Aiming at the problem of control delay and inductance deviation, which exist in the traditional deadbeat control of the full-bridge circuit, an improved deadbeat control strategy was proposed. An improved Newton interpolation prediction algorithm was proposed to compensate the delay problem of deadbeat control, and an on-line inductance identification algorithm based on double frequency sampling was proposed to correct the inductance deviation. A mathematical model of deadbeat control for fullbridge inverter was established; besides, the performance of different interpolation prediction algorithms was analyzed. An online inductor identification model is established, on the basis of which the online inductance identification compensation formula is derived. It is indicated that an output constant current of $10 \mathrm{~A}$ is available with the deadbeat control relative error of only $0.2 \%$, the grid-connected power factor up to 0.999 , and the output current's total harmonic distortion of only $2.37 \%$. The prototype experiment shows that the output current's total harmonic distortion is as low as $2.403 \%$ and the power factor is as high as 0.998 . The results show that the improved deadbeat control strategy can effectively improve the control accuracy and the quality of gridconnected power.

\section{Introduction}

Some algorithms are commonly used in full-bridge inverter control such as dual PI closed-loop control, PR control, repetitive control, and deadbeat control $[1,2]$. The dual PI closed-loop control is the most common full-bridge gridconnected control method [3-5]. Its voltage outer loop and current inner loop are controlled by PI, which has the advantages of simple control, easy implementation, and high reliability. However, the traditional PI control is difficult to achieve the ideal tracking control effect for the sinusoidal reference current [6]. In document [7], a robust deadbeat controller based on differential flatness is proposed. A mix between feedback and feedforward linearization is used to improve the parametric sensitivity for higher dynamic performance and robustness. But it greatly makes more works and complexity in controller design. In document [8], PI and QPR are used for input voltage double loop. It uses the QPR as inner current loop for searching some frequency as its high gain. In document [8], PI-fuzzy logic control is proposed. But comparing to conventional PI or deadbeat control, fuzzy logic controller needs perfect logic rules programming with expert experience. The grid current has a steady-state amplitude error and phase error, and the system has limited anti-interference ability $[9,10]$. Otherwise, the deadbeat algorithm is based on the mathematical model of the full-bridge circuit to obtain the control signal required for the next control cycle. It has the advantages of simple control structure, easy digital implementation, and fast response [11] and can reduce harmonic distortion within a wide target frequency range [12]. However, the traditional deadbeat algorithm relies on high-precision model parameters, and there is a problem of control delay in engineering applications $[13,14]$.

The PWM duty updating method proposed in document [15] is different in the modulation wave. But the work we do differently is sampling twice in one period. The former method can not only effectively decrease the grid current 
distortion and control delay, but also improve the system stability and dynamic response speed. And the latter method can effectively make the work easier with the same result. In $[16,17]$, deadbeat control is used to stabilize internal dynamics and accelerated response for a nonlinear gantry crane system. In [18], in the inner current loop, voltage compensation parameter is proposed to improve the power factor. In the voltage outer loop, an active disturbance rejection controller can improve the dynamic performance, to advance the deadbeat predictive current control in charging.

Inductive loads in the post-grid-connected stage cause grid-connected current distortion [19]. The deadbeat control uses the discrete-time model of a system to predict the amplitude of the controlled variable one or more sampling times in advance [20]. In [21], a robust predictive deadbeat grid-connected algorithm based on power feedforward is proposed. The voltage and current values of the next sampling period are predicted by linear interpolation. The weight factor interpolation algorithm is used to compensate the inductance, which is beneficial to reduce grid-connected current harmonics caused by filter inductance deviation and delay. Reactive power compensation can realize that load demand matches power generation automatically $[22,23]$. In [24], a robust predictive current deadbeat control method with reactive power compensation is proposed. The grid voltage and grid-connected current are predicted by a previous shot to enhance the robustness of the system. The active component of the reference current command is obtained by the voltage outer loop calculation, and the reactive component is extracted by the instantaneous reactive current algorithm [25]. Moreover, the control system for an ES is designed around the deadbeat control cooperating with a state observer in [26]. The two are combined to obtain the final grid-connected output current command, and the reactive power compensation is realized at the same time of the grid-connected control. In [27], an improved deadbeat current prediction control method is proposed. The linear extrapolation method is used to predict the current at time $(k+2)$ and the grid voltage at time $(k+1)$. The final calculation is $D(k+1)$. It is executed at time $k+1$, and the application of the method is a single-phase PWM rectifier, but still has a reference value. In [12, 28, 29], a robust delay compensation control method for a singlephase LCL grid-connected inverter is proposed. The capacitor current feedback delay compensation is used to calculate the half sampling period lag in the delay. The half sampling period lag generated by the zero-order keeper is compensated by increasing the zero-pole delay, thereby improving the robustness and dynamics of the system. In [30], an improved deadbeat control method for inner loop current tracking is proposed. The current prediction error correction system is added to the "two-step prediction" by using the characteristics of error voltage increment and parity cancellation. It not only effectively reduces the voltage and current sampling error, but also compensates the control delay, and finally improves the control accuracy of the deadbeat algorithm. Quasi-PR control is used in the closed-loop algorithm of the poststage current in the fullbridge circuit, which can achieve fast dynamic response, eliminate frequency jitter, and no static error in the steady state. It can track the set parallel current quickly and accurately and realize the grid connection with the energy unit power factor, but there are some programming difficulties.

In another study, the strategy of grid connection is discussed, and the idea that mean value of output current feedback control combined with synchronization phaselocked control is brought forward; it shows that the frequency and phase of output current can follow those of utility voltage, and the requirement of sine output current and unit power factor can be also achieved using the control strategy.

Aiming at the problem of control delay and inductance deviation for traditional deadbeat control, this paper studies an improved deadbeat control strategy and proposes an improved Newton interpolation prediction delay compensation algorithm and online inductance identification compensation algorithm based on frequency-doubling sampling. It effectively improves the output current control accuracy and improves the grid-connected power quality. The block diagram is shown in Figure 1.

\section{Full Bridge without Difference Beat Control}

As a common digital PWM control algorithm, the control algorithm based on the physical law establishes the precise mathematical model of the controlled object based on the physical law. According to the state equation of the controlled object and the feedback signal of the system, the PWM signal duty ratio of the next control cycle is calculated, and a digital PWM control is completed. The deadbeat control describes the complex system through the mathematical language, which helps to understand the relationship between the various control signals and facilitates the realization of the digital realization of the algorithm [31].

The realization of the deadbeat control algorithm firstly needs to establish the mathematical model of the full-bridge inverter circuit and get the relationship between the fullbridge circuit drive duty ratio and the output current. The full-bridge circuit model is shown in Figure 2. When modeling, the DC bus voltage $V_{\mathrm{BUS}}$ can be approximated to a constant. Schematic diagram of the relationship between grid voltage $U_{\text {grid }}$, grid output current $I_{\text {OUT }}$, and duty ratio $D$ is shown in Figure 3.

According to Kirchhoff's voltage law and inductance equation, the state equation of the full-bridge inversion can be obtained and then discretized:

$$
U_{\text {ab_ave }}(n)=L \frac{I(n+1)-I(n)}{T(n)}+U_{\text {grid_ave }}(n) .
$$

In the formula, $U_{\text {grid_ave }}(n)$ is the average value of the grid voltage within the switching period, and $U_{\mathrm{ab} \_ \text {ave }}(n)$ is the average of $U_{\mathrm{ab}}$ in the switch cycle, and there is $U_{\mathrm{ab} \_ \text {ave }}$ $(n)=D(n) V_{\mathrm{BUS}}, D(n)$ is the drive duty ratio of the switching MOSFET, and $V_{\text {BUS }}$ is the voltage of the BUS capacitor.

Because the switching period is very small, the sinusoidal voltage during switching can be regarded to be approximately linear; thus, 


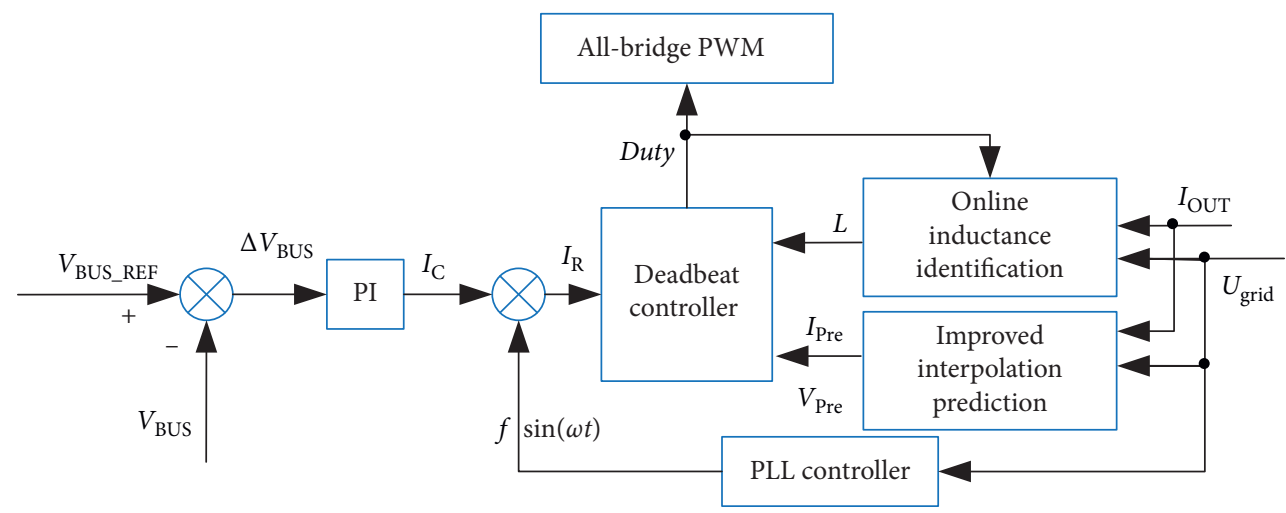

FIGURE 1: Block diagram of improved deadbeat control strategy for full bridge.

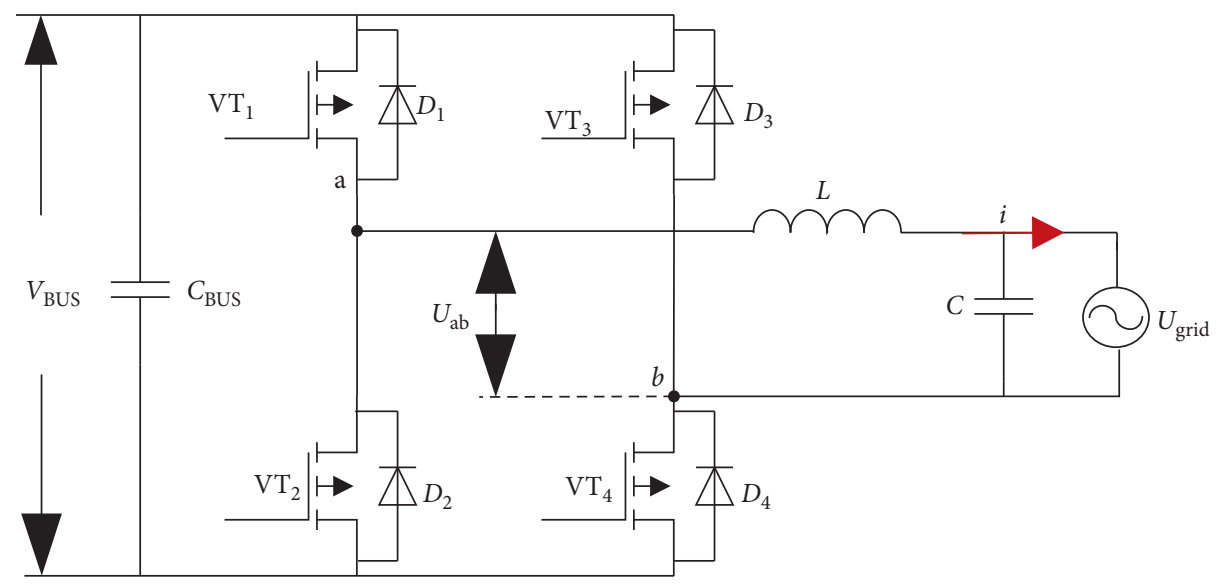

FIGURE 2: Full-bridge circuit model of deadbeat control algorithm.

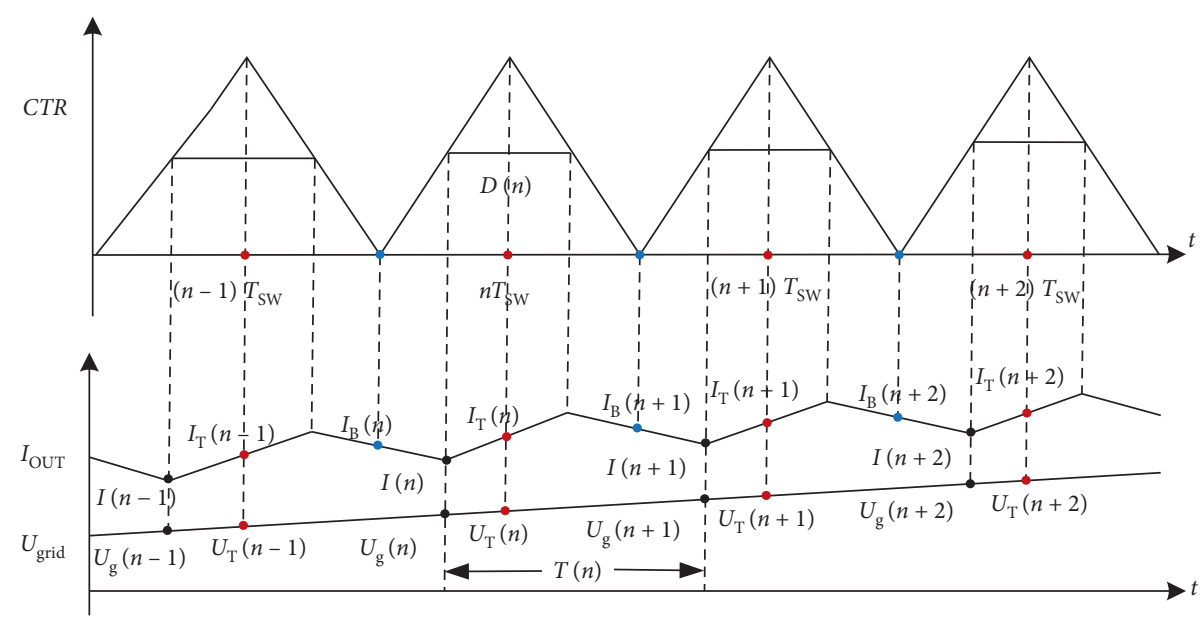

FIGURE 3: Diagram of the relation between the output current and voltage and the duty ratio.

$$
\begin{aligned}
U_{\text {grid_ave }}(n) & =\frac{U_{\mathrm{g}}(n)+U_{\mathrm{g}}(n+1)}{2}, \\
U_{\mathrm{g}}(n+1)-U_{\mathrm{g}}(n) & =U_{\mathrm{g}}(n)-U_{\mathrm{g}}(n-1) .
\end{aligned}
$$

In practical engineering applications, the main DSP chip carries out AD sampling at the PWM triangle carrier vertex. The sampling results of the voltage and output current of the power grid are $U_{\mathrm{T}}(n)$ and $I_{\mathrm{T}}(n)$, respectively, because the interval between the starting point of the switch period is very short, so the approximate relationship can be obtained: $U_{\mathrm{g}}(n) \approx U_{\mathrm{T}}(n)$ and $I(n) \approx I_{\mathrm{T}}(n)$. At the same time, the relationship $T(n) \approx T_{\text {SW }}$ can be obtained because the duty cycle of the adjacent period is very small.

Calculating by formulas (1)-(3), it is obtained and shown 


$$
D(n)=L \frac{I_{\mathrm{R}}(n+1)-I_{\mathrm{T}}(n)}{V_{\mathrm{BUS}} T_{\mathrm{SW}}}+\frac{3 U_{\mathrm{T}}(n)-U_{\mathrm{T}}(n-1)}{2 V_{\mathrm{BUS}}} .
$$

In the formula, $T_{\mathrm{SW}}$ is the main control DSP chip fullbridge PWM control signal period, and $I_{\mathrm{R}}(n+1)$ is the output current reference value of the No. $(n+1)$ switching cycle.

At this point, the mathematical modeling of the control algorithm of the full-bridge inverter circuit is completed. The full-bridge circuit drive duty ratio of the beat free algorithm can be obtained through formula (4), and the output current of the next switch period can be controlled.

\section{Improved Newton Interpolation Prediction Algorithm}

In the process of digital control, the traditional deadbeat control algorithm, due to the EPWM register and the PWM drive waveform update mechanism, should be in the PWM duty cycle $D(n)$ output in No. $(n)$ control cycle and need to be updated in No. $(n+1)$ cycle, so there is a "delay one beat" problem.

In order to solve the problem of control delay in the process of digital control, the researchers introduced the prediction algorithm on the basis of the traditional beat control algorithm. The core idea is to complete the $\mathrm{AD}$ sampling of the relevant operation parameters at the vertex $(n-1) T_{\mathrm{SW}}$ of the triangular carrier of the $(n-1)$ control period. Then through correlation prediction algorithm, we get the $U_{\mathrm{T}}(n)$ and $I_{\mathrm{T}}(n)$ needed to calculate $D(n)$. Then the PWM driver with the duty cycle of $D(n)$ is output in the $N$ control cycle. And the problem of control delay is eliminated and real-time control of deadbeat algorithm is realized.

The more common prediction algorithms are repetitive control prediction algorithm, linear fitting algorithm, and Newton interpolation algorithm [32]. The steady-state accuracy of the repetitive control prediction algorithm is high, but the dynamic response performance is poor [33], while the linear fitting prediction algorithm has the characteristics of less computation and easy to realize, but there are also insufficient [34], such as big error, weak antijamming capability, and so on. Compared with the linear fitting prediction algorithm, Newton interpolation prediction algorithm has smaller prediction error, but the computational complexity of the algorithm also increases [22]. In this paper, based on the traditional Newton interpolation prediction algorithm, an improved interpolation algorithm is proposed, and "bit operation" is introduced on the basis of the traditional Newton interpolation prediction algorithm. The multiplication and division of digital controller resources is reduced by Newton interpolation order optimization and parameter matching, which can effectively reduce the resources needed for the algorithm. According to the characteristics of linear fitting, the prediction formula of linear fitting is obtained:

$$
f(n+1)=\frac{3 y(n)-y(n-1)}{2}(n \geq 1) .
$$

In the formula, $y(n)$ and $y(n-1)$ are the results of the $\mathrm{AD}$ sampling of the current cycle and the last cycle of the predicted parameters, and $f(n+1)$ is the predicted value of the predicted parameter in the next cycle.

Based on Newton interpolation formula and engineering experience, an improved Newton interpolation prediction formula is obtained:

$$
\begin{aligned}
f(n+1)= & (y(n) \ll 2)-(y(n-1) \ll 2) \\
& -(y(n-1) \ll 1)+(y(n-2) \ll 2)-y(n-3) .
\end{aligned}
$$

In the formula, $y(n), y(n-1), y(n-2)$, and $y(n-3)$ are the $\mathrm{AD}$ sampling results of the predicted parameters in the last four cycles, while $f(n+1)$ is the predicted value of the predicted parameters in the next cycle.

In order to verify the prediction accuracy of the linear fitting prediction algorithm, the Newton interpolation prediction algorithm, and the improved interpolation prediction algorithm, the Simulink simulation model of the error analysis of the three forecasting methods is established. Since the ADC range of TMS320F2808 [35] is 0-4096 and the $400 \mathrm{ADC}$ interrupts are triggered in a sinusoidal cycle, the predicted signal is a discrete sinusoidal signal whose function expression is

$$
\begin{aligned}
y(n)=2048 \cdot \sin (100 \pi t)+2048 \\
t=50 \times 10^{-6} n, n=0,1, \ldots, N .
\end{aligned}
$$

The prediction error simulation results of the three deadbeat predictive control algorithms are shown in Figure 4. The simulation results show that the error of the linear fitting algorithm is cosine law, and the maximum error is 17 . The Newton interpolation algorithm has less error and is always in the range of $[-6,6]$. The accuracy of the improved interpolation prediction algorithm is the same as that of the Newton interpolation algorithm. The simulation results show that compared with the linear fitting algorithm, the Newton interpolation algorithm has higher prediction accuracy. At the same time, when the first prediction is carried out, the calculation of the linear fitting algorithm requires the first two $\mathrm{AD}$ sampling results to participate in the prediction. Therefore, the linear fitting prediction algorithm only needs to enter the normal prediction mode in 2 control cycles $(100 \mu \mathrm{s})$, and the interpolation prediction algorithm can complete the prediction because it requires four $\mathrm{AD}$ sampling results, so the dynamic response time of 4 control cycles $(200 \mu \mathrm{s})$ is needed.

In order to compare the advantages and disadvantages of the three algorithms more intuitively, through simulation and experiment, quantitative analysis is made for prediction accuracy, operation steps, and resource occupancy of the digital controller. The analysis and comparison results of the three deadbeat predictive control algorithms are shown in Table 1. Absolute error accumulation is the cumulative result of a total of 400 prediction errors in a single grid voltage cycle $(0.02 \mathrm{~s})$. The time consumption of the algorithm is the time required for the three prediction algorithms to run 400 times on the DSP chip, which directly reflects the resource 

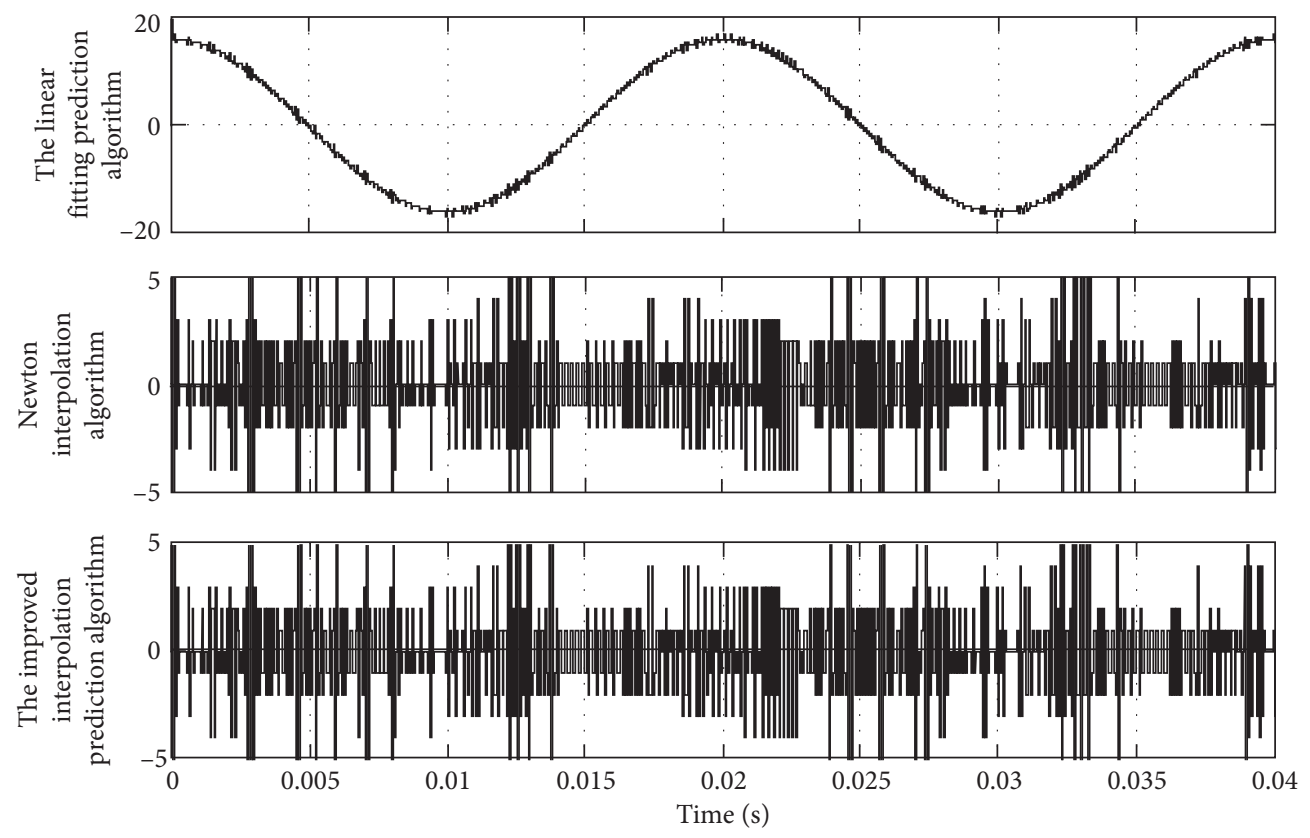

FIgURE 4: Prediction error simulation results of three deadbeat prediction algorithms.

TABLE 1: Analysis and comparison of three deadbeat predictive control algorithms.

\begin{tabular}{lccc}
\hline Performance index & $\begin{array}{c}\text { Linear } \\
\text { interpolation }\end{array}$ & $\begin{array}{c}\text { Newton } \\
\text { interpolation }\end{array}$ & $\begin{array}{c}\text { Improved } \\
\text { interpolation }\end{array}$ \\
\hline $\begin{array}{l}\text { Absolute error } \\
\text { accumulative }\end{array}$ & 4103 & 809 & 809 \\
$\begin{array}{l}\text { Addition and } \\
\text { subtraction } \\
\text { operation }\end{array}$ & 1 & 3 & 5 \\
$\begin{array}{l}\text { Multiplication and } \\
\text { division operation }\end{array}$ & 3 & 3 & 0 \\
$\begin{array}{l}\text { Bit operation } \\
\text { Time consumption } \\
\text { of algorithm } \\
\text { calculation }\end{array}$ & 0 & 0 & 4 \\
\hline
\end{tabular}

occupancy of the digital controller. During the operation of the prediction algorithm, the corresponding indicator pin of the DSP chip is set to the high-level output. The oscilloscope channels 1,2, and 3 are time-consuming test waveforms calculated by linear interpolation, Newton interpolation, and improved interpolation prediction algorithms, respectively, as shown in Figure 5.

The results of simulation and test show that compared with the linear fitting, the absolute error of the improved interpolation prediction algorithm is reduced by $80 \%$ and the resource occupancy rate of the digital controller is only $19.4 \%$. Compared with the traditional Newton interpolation prediction algorithm, the improved interpolation prediction algorithm reduces the resource occupancy of the digital controller by $20.31 \%$. The results of the study show reasonable prediction order selection and operation optimization. It makes the improved interpolation prediction algorithm maintain higher prediction accuracy and reduce the amount of calculation, so it has higher engineering application value.

\section{Online Inductance Identification Compensation Algorithm Based on Frequency Multiplication Sampling}

4.1. Online Inductance Identification Algorithm Modeling. The algorithm is a control algorithm based on the mathematical modeling of the hardware circuit, which depends on the accuracy of the electrical parameters, especially for the parameter change of the filter inductor. In the process of fullbridge inverting, the inductance of the grid-connected filter will change by the effective value of its current, temperature, and the switching frequency of the inductor, which leads to the reduction in control precision, the increase in the harmonics of the grid current, and the increase in the phase difference between the grid voltage and the grid-connected current [36]. Therefore, this paper proposes an on-line inductor identification compensation algorithm based on frequency-doubling sampling, which improves the $\mathrm{AD}$ sampling frequency to two times of the PWM carrier frequency. The online identification of inductance parameters of deadbeat control model is realized. The inductance identification value is used to correct the electrical parameters of the control model. The control precision of the deadbeat algorithm is improved effectively.

The realization of online inductance identification compensation algorithm based on frequency multiplication sampling is presented in this paper. In a PWM carrier cycle, an output current $\mathrm{AD}$ sampling is added on the basis of deadbeat control, making the sampling frequency of the output current $\mathrm{AD}$ two times that of the PWM carrier frequency. The new AD sampling of the nth PWM carrier cycle is located at the beginning of the carrier, and the $\mathrm{AD}$ 


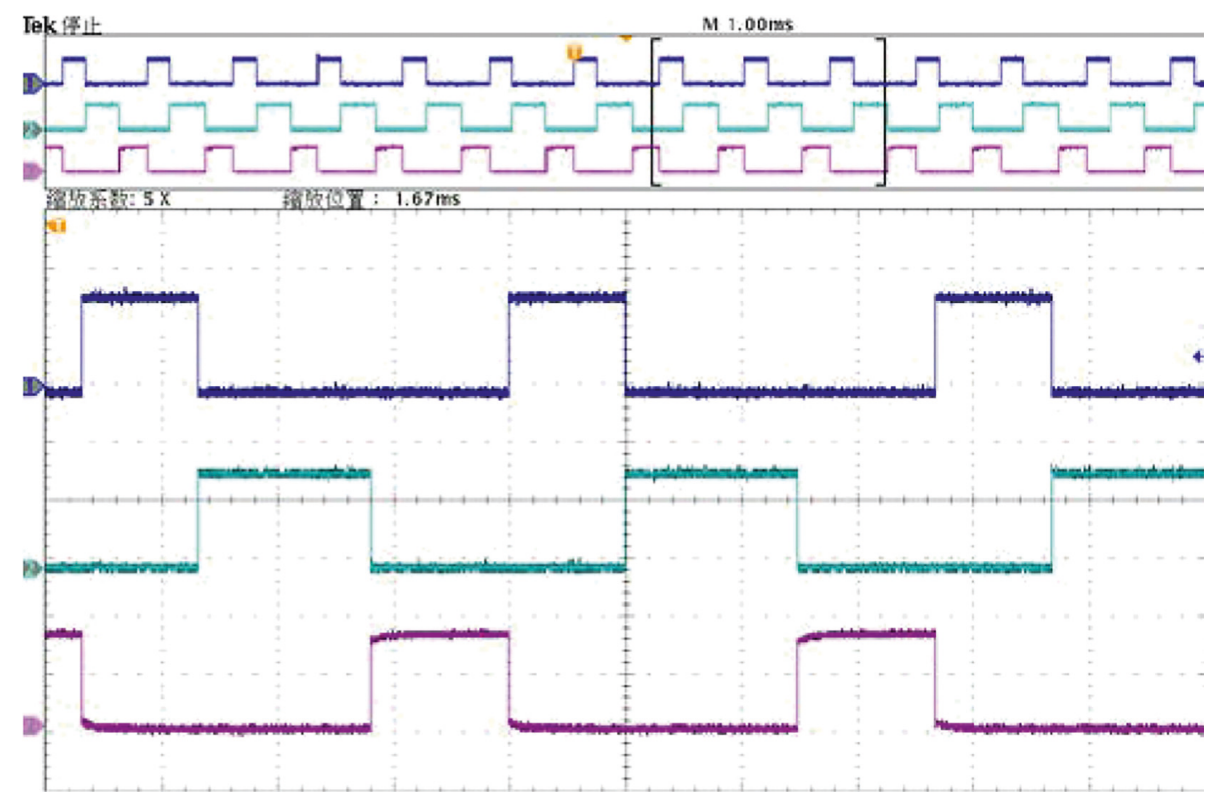

FiguRE 5: Computational time-consuming test results of three deadbeat prediction algorithms.

sampling result of the output current is $I_{\mathrm{B}}(n)$, as shown in Figure 3.

The state equation of the full-bridge inversion can get the transient equation of the whole bridge working in the freewheeling mode.

$$
\begin{aligned}
& \frac{2 L(n) \cdot\left(I(n)-I_{\mathrm{B}}(n)\right)}{(1-D(n)) \cdot T_{\mathrm{SW}}}+U_{\text {grid_ave }}(n-1) \\
& \quad=U_{\text {ab_ave }}(n-1)=0 .
\end{aligned}
$$

Similarly, the transient equation of the whole bridge in conduction mode is

$$
\begin{gathered}
\frac{2 L(n) \cdot\left(I_{\mathrm{T}}(n)-I(n)\right)}{D(n) \cdot T_{\mathrm{SW}}}+U_{\text {grid_ave }}(n-1) \\
=U_{\text {ab_ave }}(n-1)=V_{\text {BUS }}(n-1) .
\end{gathered}
$$

The inductance identification value of the $n$ PWM carrier cycle is

$$
L_{\mathrm{M}}(n)=\frac{T_{\mathrm{SW}}\left(D(n) \cdot V_{\mathrm{BUS}}(n-1)-U_{\text {grid_ave }}(n-1)\right)}{2 \cdot\left(I_{\mathrm{T}}(n)-I_{\mathrm{B}}(n)\right)} .
$$

At the same time, in order to reduce the disturbance of switch noise to inductance identification, the inductor identification area is limited to allow sufficient time margin between the $\mathrm{AD}$ sampling point and the IGBT switching time.

Among them, the relationship between time margin and carrier period is $t_{\mathrm{m}}=\beta T_{\mathrm{SW}}$.

$\beta$ is a time margin factor and $0<\beta<0.25$. Finally, the duty cycle of the inductor identification area in the DSP control software should be satisfied:

$$
2 \beta \leq D(n) \leq 1-2 \beta \text {. }
$$

Because the full-bridge circuit works normally, inductance changes slowly. In order to prevent the oscillation of the deadbeat control system in the next control model, the low-pass filtering algorithm is added when the inductance value of the next cycle control model is compensated by the inductance identification value. That is, the inductance compensation result of the $n+1$ control cycle is

$$
L(n+1)=\alpha L_{\mathrm{M}}(n)+(1-\alpha) L(n)(0<\alpha<1) .
$$

In the formula, $\alpha$ is the filter coefficient of the compensation algorithm, $L_{\mathrm{M}}(n)$ is the latest inductance identification value, and $L(n)$ is the inductance compensation result of the No. $(n)$ control period.

4.2. Simulation and Analysis of Online Inductance Identification Algorithm. In order to verify the influence of online inductance identification compensation algorithm on deadbeat control strategy based on frequency multiplication sampling, the Simulink simulation model of online inductance compensation algorithm is established. The influence of inductance error on the current harmonic distortion ATHD [37] in the deadbeat control algorithm is studied because the grid-connected LC filter is also the influencing factor of the grid current ATHD. Therefore, the parameters of the LC filter remain unchanged in the simulation process, by modifying the initial value of the inductance of the deadbeat control model. The influence of different inductance errors on power quality in grid-connected deadbeat control algorithm is studied.

In formula (4), the value of some hardware parameters should be selected and designed to calculate the duty of next cycle, which are, respectively, $L, V_{\mathrm{BUS}}$, and $T_{\mathrm{sw}}$. Because the capacitor is not used for the calculation, it is not discussed in this paper. 
BUS capacitor is the input direct energy of the inverter circuit, so the voltage of BUS is necessary to be higher than the peak voltage of the grid voltage. Thus, the value of $400 \mathrm{~V}$ is frequently used for parameter $V_{\mathrm{BUS}} . T_{\mathrm{sw}}$ means the PWM frequency of the PWM full bridge. Higher frequency means smaller components but higher switching loss. After selection, $20 \mathrm{kHz} \sim 25 \mathrm{kHz}$ is set in DSP PWM mode in the experiment. When it is $25 \mathrm{kHz}, T_{\mathrm{sw}}$ is equal to $40 \mathrm{us}$.

In the full-bridge inverter, the output filter inductor $L$ is a key component, and the ripple of the grid current directly affects the quality of the power grid. The smaller the ripple is, the smaller the pollution of high-order harmonic is, and the higher the quality of electric energy is; on the contrary, the larger the harmonic pollution is, the worse the quality of electric energy is. Therefore, the design scheme should minimize the size of ripple. According to the inductance equation (13), $L$ is selected as $2.5 \mathrm{mH}$ and splatted into 2 parts.

$$
L=\frac{V_{\mathrm{g} \max }\left(V_{\mathrm{BUS}}-V_{\mathrm{g} \max }\right) T_{\mathrm{sw}}}{\Delta i V_{\mathrm{BUS}}} .
$$

The simulation parameters are that the voltage of the DC bus is $400 \mathrm{VDC}$, the voltage of the power grid is $220 \mathrm{VAC}$, the frequency is $50 \mathrm{~Hz}$, the inductance of the LC filter is $2 \times 1.25 \mathrm{mH}$, the filter capacitance is $3.3 \mu \mathrm{F}$, the output current is $10 \mathrm{~A}$, and the full bridge circuit IGBT is controlled by the drive duty ratio of the deadbeat algorithm. When the online inductance identification compensation algorithm based on frequency doubling sampling is disabled, the inductance of the beat free algorithm control model is equal to the initial inductance value, that is, the filter coefficient $\alpha=0$ of formula (12). When the online inductance identification compensation algorithm is enabled, the inductance of the deadbeat control model will be compensated according to the inductance identification value and the low-pass filter coefficient $\alpha=0.1$.

When the true value of the filter inductance is $2.5 \mathrm{mH}$ and the initial inductance of the deadbeat control model is $0.5 \mathrm{mH}$, the online inductance identification compensation algorithm is not enabled, and the simulation waveform of the voltage and output current of the power grid is shown in Figure 6(a). The simulation results show that there is phase difference between the output current and the grid voltage, and the sinusoidal period of the output current is equal to $19.4 \mathrm{~ms}$. The output current is fast Fourier transformed (Fast Fourier Transformation, FFT), the output current harmonic distortion is $4.50 \%$, the fundamental wave amplitude is $8.183 \mathrm{~A}$, and the output current is only $5.794 \mathrm{~A}$, far less than the $10 \mathrm{~A}$ reference value.

At this time, the online inductance identification compensation algorithm is opened, and the simulation waveform of the voltage and output current of the power grid is shown in Figure 6(b). After the online inductance identification compensation works, the inductance compensation result of the deadbeat control model is shown as in Figure 7(a). The simulation results show that the phase of the output current is the same as that of the grid voltage, the sinusoidal period is equal to $20.0 \mathrm{~ms}$, and the amplitude of the output current is normal. The output current is fast Fourier transformed (Fast
Fourier Transformation, FFT). The output current harmonic distortion is only $2.39 \%$, the amplitude of the fundamental wave is $14.22 \mathrm{~A}$, and the effective value of the output current is $10.06 \mathrm{~A}$. At the same time, the inductance value of the no beat control model is quickly adjusted from the initial $0.5 \mathrm{mH}$ to the true value of $2.5 \mathrm{mH}$, but due to the error of the inductance identification, the inductance compensation result is finally controlled at $2.5 \mathrm{mH} \pm 0.15 \mathrm{mH}$, and the maximum relative error is $6 \%$.

When the initial inductance of the deadbeat control model is $5.0 \mathrm{mH}$, the inductance compensation result of the deadbeat control model after the online inductance identification is shown in Figure 7(b), and the maximum relative error between the inductance and the true value of the compensated control model is only $4.8 \%$.

In order to further study the effect of online inductance identification and compensation algorithm on improving power quality and improving control accuracy of gridconnected power system, the power quality of grid connected before and after inductor compensation algorithm is simulated and analyzed. When the online inductance identification compensation algorithm is not implemented, the inductance parameter of the deadbeat control model is always the initial value. If the online inductance identification compensation is used, the inductance value of the deadbeat control model will gradually be close from the initial inductance to the actual inductance value after the compensation, and the simulation results of the grid power quality are shown in Figure 8.

The simulation results show that the less the inductance value of the filter inductor, the smaller the inductance value of the control model, the greater the output current harmonic distortion, and the smaller the effective value of the output current, compared with the true value of the filter inductance without the inductance identification compensation. When there is no online inductor identification compensation, with the increase of the initial inductance value, the output current ATHD is improved, the improvement effect is gradually weakened, and the increase of the value of the effective value is gradually reduced. When the initial value of the inductance of the control model is equal to the true value, the effective value of the output current is $10.03 \mathrm{~A}$, and the relative error is only $0.3 \%$. When the online inductor identification compensation algorithm is used, the output current harmonic distortion is always controlled at about $2.40 \%$ even if there is a big error between the initial value and the true value of the output current control model, the output current is about $10 \mathrm{~A}$, and the maximum relative error is only $0.6 \%$. The simulation results show that the online inductance identification and compensation algorithm based on frequency-doubling sampling can effectively improve the precision of output current control and improve the quality of grid-connected power.

\section{Simulation and Analysis of Improved Deadbeat Control Strategy}

At this point, the control delay compensation algorithm based on improved interpolation prediction and the power 

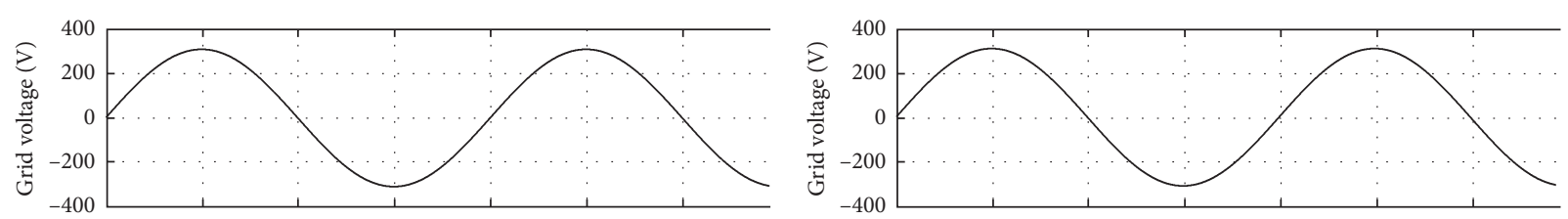

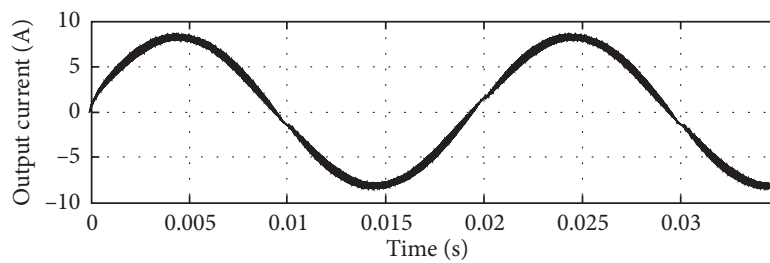

(a)

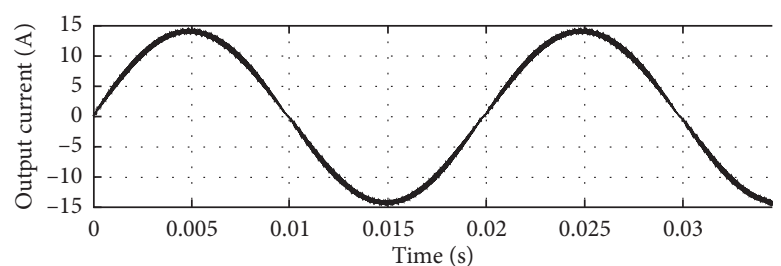

(b)

Figure 6: Simulation waveform of grid voltage and output current with initial inductance of $0.5 \mathrm{mH}$. (a) Noninductance compensation waveform. (b) Inductance compensation waveform.

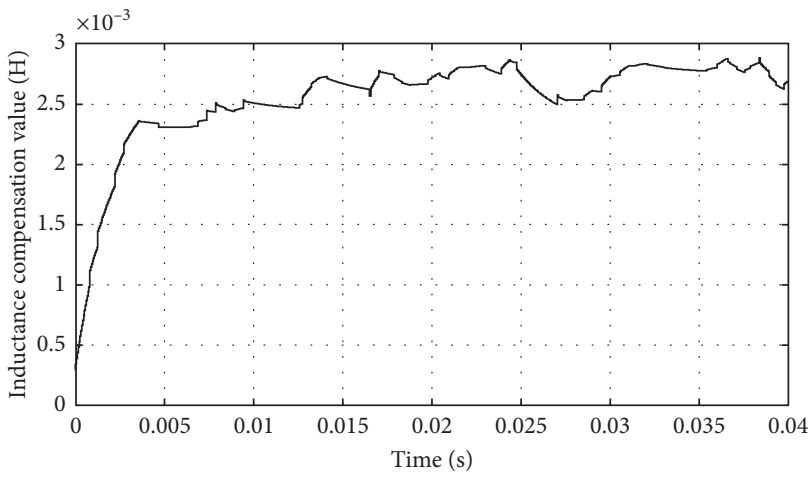

(a)

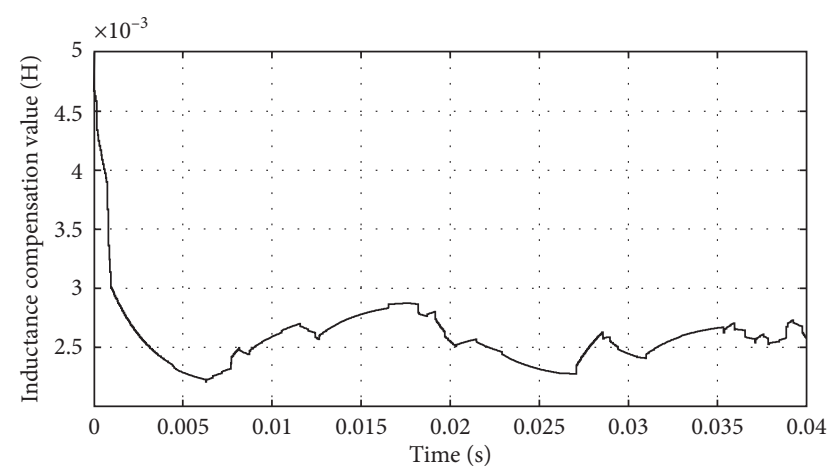

(b)

FIGURE 7: Compensation results of online inductance identification for nondifferential beat control. (a) Inductance initial value $0.5 \mathrm{mH}$ compensation result. (b) Inductance initial value $5 \mathrm{mH}$ compensation result.

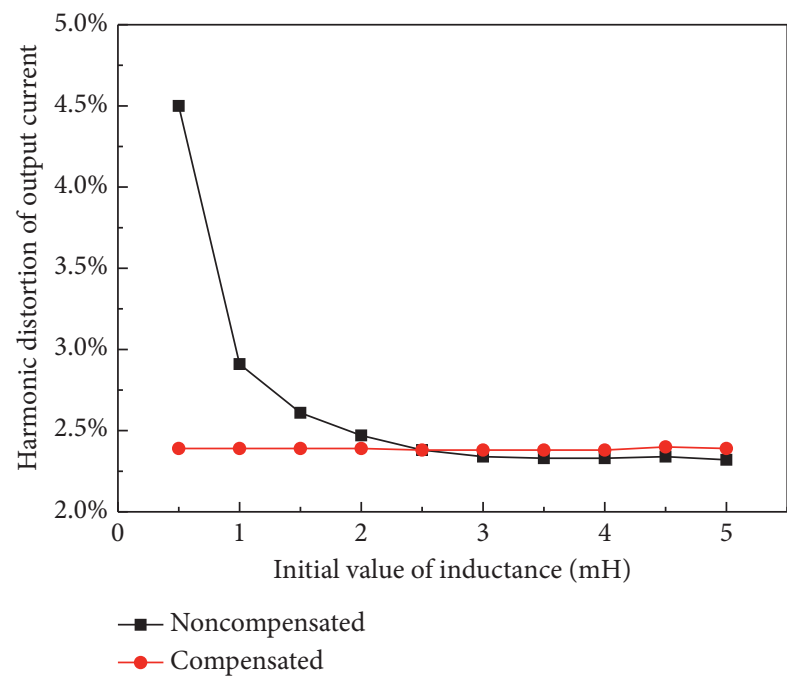

(a)

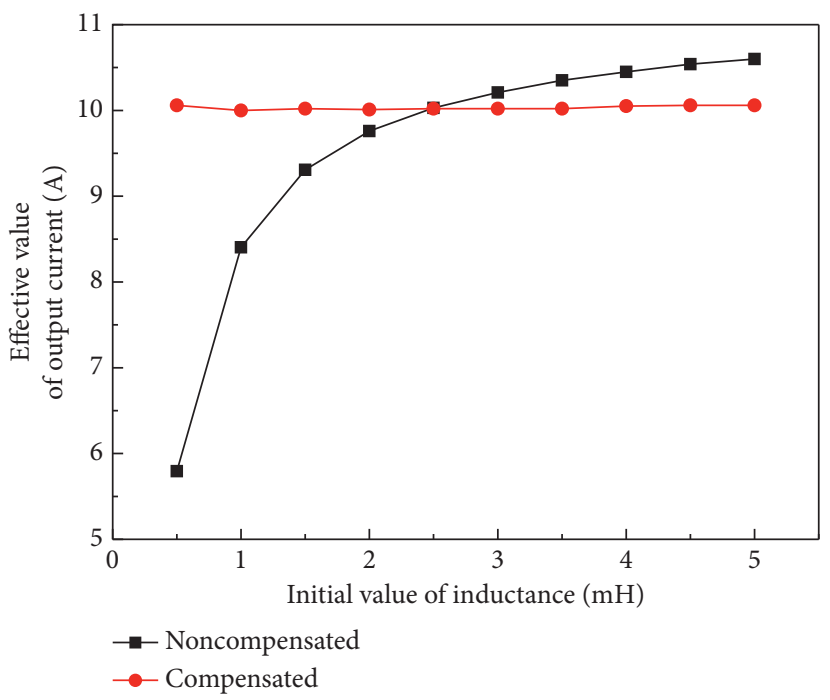

(b)

FiguRE 8: Influence of different inductance errors on harmonic distortion and effective value of deadbeat grid-connected output current. (a) Curve of harmonic distortion of output current. (b) Curve of effective value change of output current. 


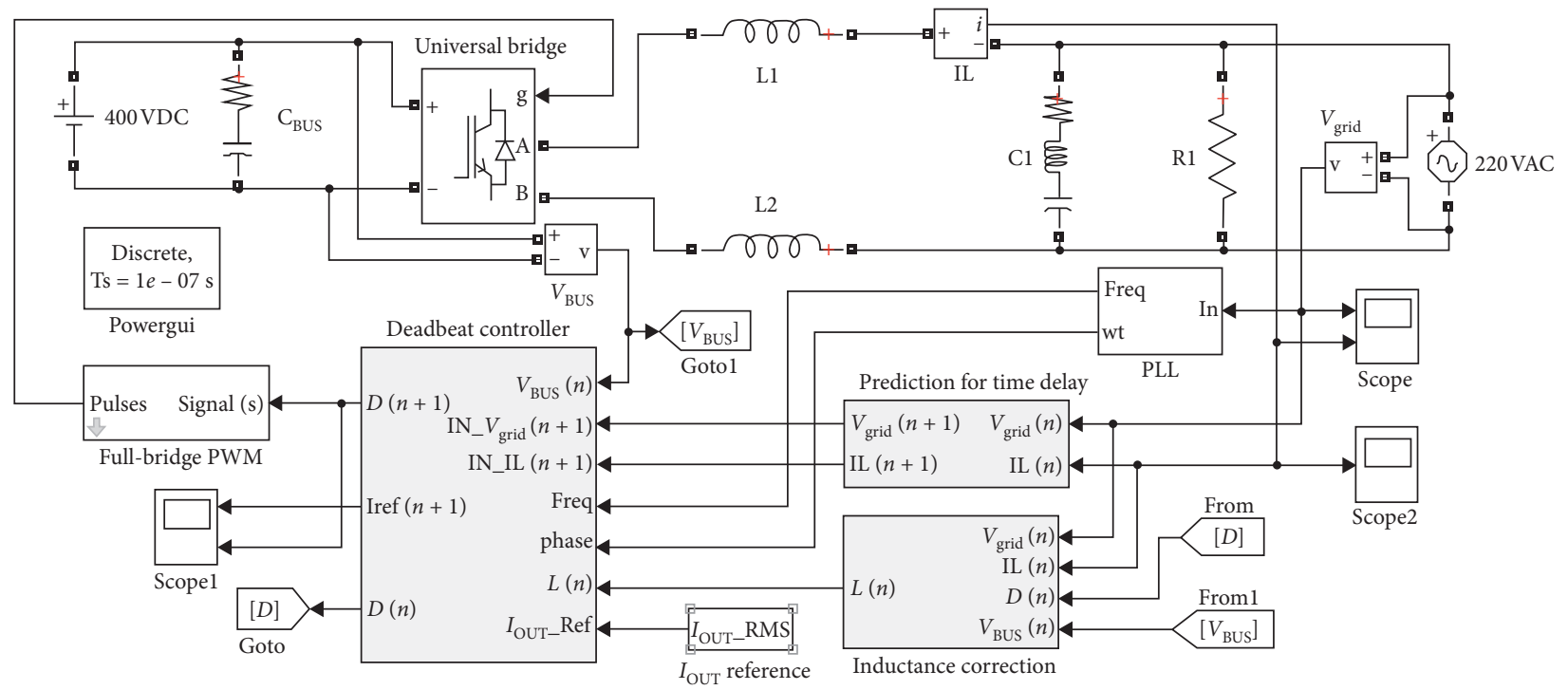

FIGURE 9: Simulation model of improved deadbeat grid-connected control strategy.
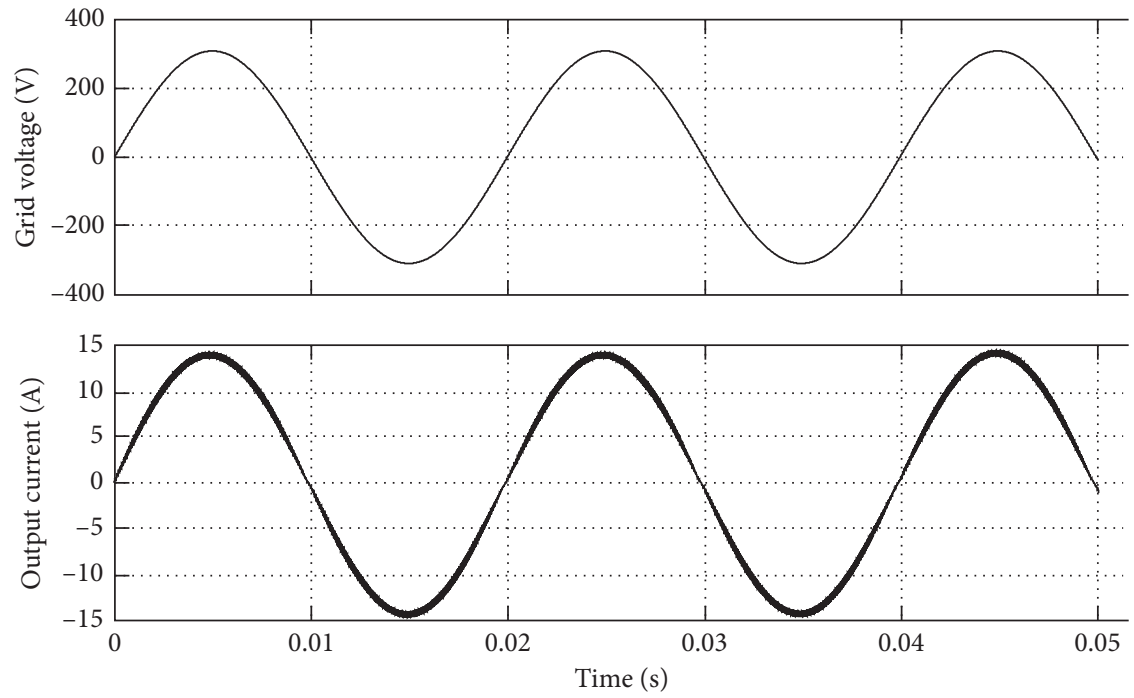

FIGURE 10: Improved deadbeat control strategy output current and voltage waveforms.

feedback unit deadbeat control strategy based on the online inductance identification and compensation algorithm based on frequency-doubling sampling are proposed, and the simulation model of the deadbeat control strategy is established by using Simulink simulation software, as shown in Figure 9.

The simulation results of the output current reference value of $10 \mathrm{~A}$ are shown in Figure 10. The simulation results show that the effective value of the output current is $10.02 \mathrm{~A}$, the control error of the beat free is only $0.2 \%$, and the output current is always in the same phase with the power grid voltage, and the power factor of the grid is 0.9999 , and the high-power quality is shown by the grid-connected transmission.

At the same time, the harmonic distortion of the output current is analyzed by the FFT function of the power module in Simulink [38], and the result is shown in Figure 11. The
FFT results show that the harmonic distortion of the output current is only $2.37 \%$, the main harmonic component is the odd harmonic, and the harmonic components gradually decrease with the increase of the harmonic frequency, and the high-frequency harmonic of the output current is effectively suppressed.

In order to further verify the dynamic response performance of deadbeat control strategy, the reference value of output current changes from $10 \mathrm{~A}$ to $8 \mathrm{~A}$ at $0.02 \mathrm{~s}$. At $0.045 \mathrm{~s}$, the reference value of the output current is changed from $8 \mathrm{~A}$ to $12 \mathrm{~A}$, and the simulation results are shown in Figure 12. At $0.02 \mathrm{~s}$, the output current is just zero. After the reference value changes, the output current tracking is completed in the next control cycle. At $0.045 \mathrm{~s}$, the output current is at peak value, which requires $0.2 \mathrm{~ms}$ (4 control cycles) to complete the output current tracking. It can be seen that the proposed deadbeat control strategy has good dynamic 


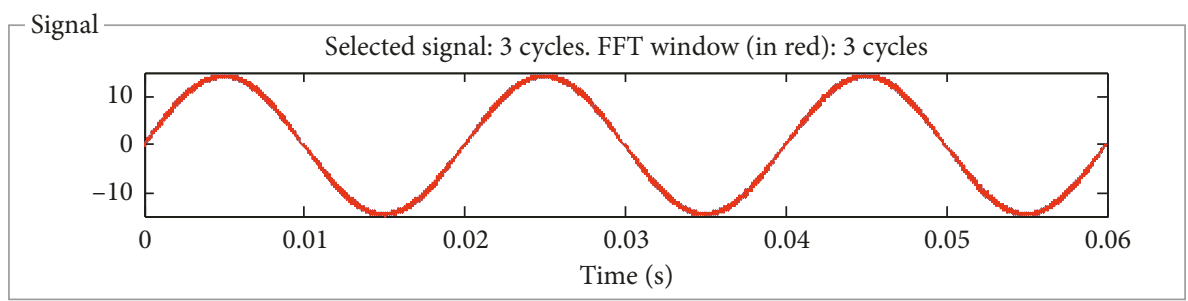

(a)

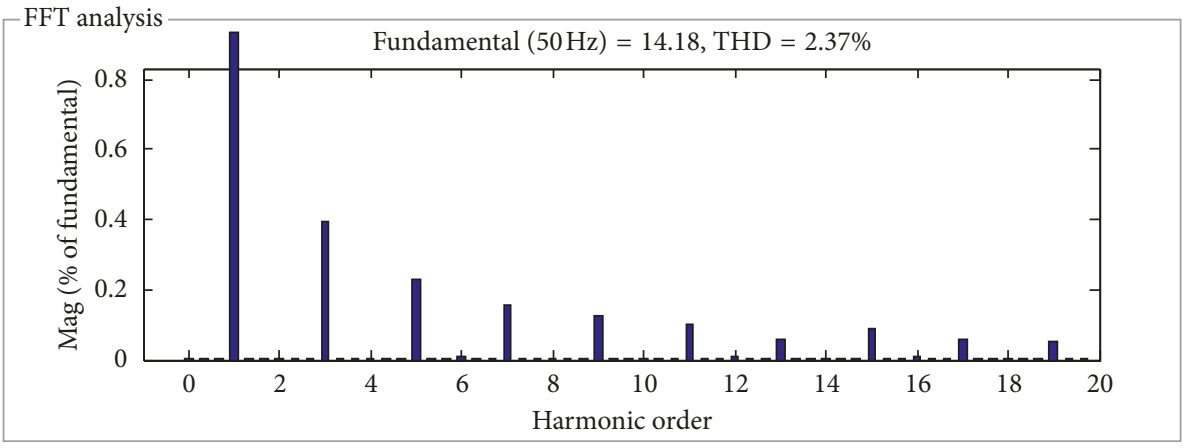

(b)

Figure 11: Harmonic current analysis of improved deadbeat control strategy.
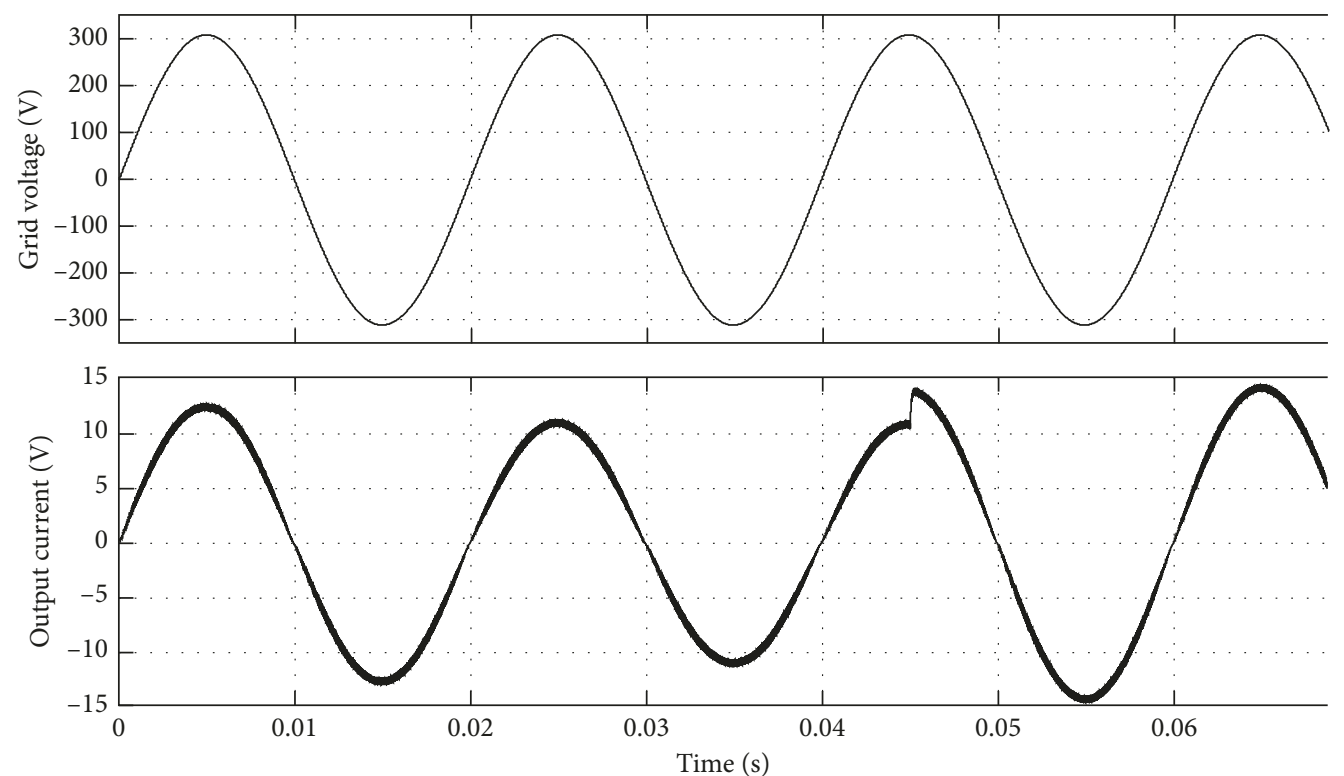

FIGURE 12: Improved deadbeat control strategy for grid-connected output current and voltage waveforms when power abrupt changes.

response performance and can quickly complete the dynamic tracking and adjustment of the output current when the power of the front stage is changed.

\section{Experimental Analysis on Improved Deadbeat Control Strategy}

In order to verify the validity of the improved deadbeat control strategy for the full-bridge inverter circuit and to test the power quality of its grid-connected power supply comprehensively, a $3 \mathrm{~kW}$ nonisolated photovoltaic gridconnected inverter is developed, as shown in Figures 13 and
14. The power circuit selects the "Boost + full bridge" topology. The PM1000 + power analyzer is used to measure the harmonic distortion of the grid-connected current of the $3 \mathrm{~kW}$ nonisolated PV grid-connected inverter under different input voltages and powers, and the ATHD and power factor are measured. The test data record is shown in Table 2. According to the test data, the curves of performance parameters with power are plotted as shown in Figure 13.

The experimental results show that the harmonic distortion of grid-connected current decreases with the increase of power in the prototype of $3 \mathrm{~kW}$ nonisolated photovoltaic grid-connected inverter. At the same time, with the increase 


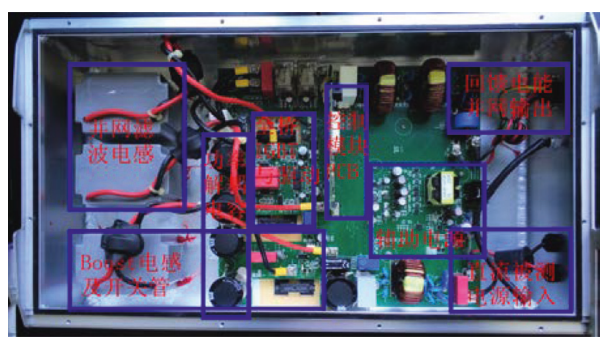

FIGURE 13: $3 \mathrm{~kW}$ grid-connected inverter.

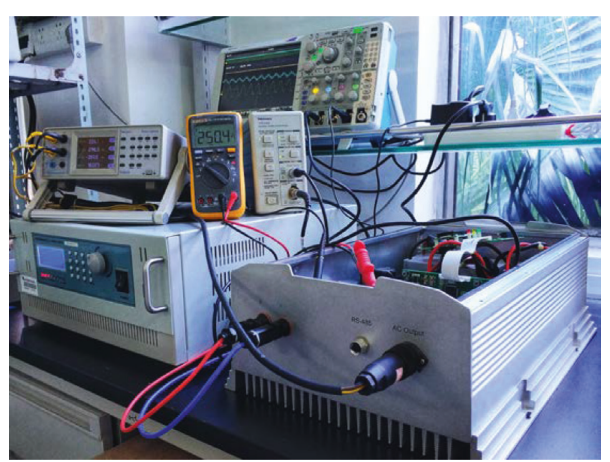

FigURE 14: $3 \mathrm{~kW}$ grid-connected inverter experimental platform.

TABLE 2: Electrical energy feedback quality test results.

\begin{tabular}{|c|c|c|c|c|c|c|}
\hline \multirow{2}{*}{ Input power $(\mathrm{W})$} & \multicolumn{3}{|c|}{ ATHD (\%) } & \multicolumn{3}{|c|}{ Power factor } \\
\hline & $200 \mathrm{~V}$ & $250 \mathrm{~V}$ & $300 \mathrm{~V}$ & $200 \mathrm{~V}$ & $250 \mathrm{~V}$ & $300 \mathrm{~V}$ \\
\hline 400 & 10.549 & 10.073 & 9.907 & 0.947 & 0.950 & 0.951 \\
\hline 800 & 5.183 & 5.313 & 5.421 & 0.987 & 0.986 & 0.985 \\
\hline 1200 & 3.507 & 3.823 & 3.806 & 0.995 & 0.994 & 0.992 \\
\hline 1600 & 2.922 & 3.412 & 3.712 & 0.997 & 0.996 & 0.994 \\
\hline 2000 & 2.534 & 2.784 & 2.963 & 0.998 & 0.997 & 0.997 \\
\hline 2400 & 2.474 & 2.934 & 3.043 & 0.998 & 0.996 & 0.997 \\
\hline 2800 & 2.403 & 2.555 & 2.887 & 0.998 & 0.998 & 0.998 \\
\hline 3200 & 2.784 & 2.504 & 2.784 & 0.998 & 0.998 & 0.998 \\
\hline
\end{tabular}

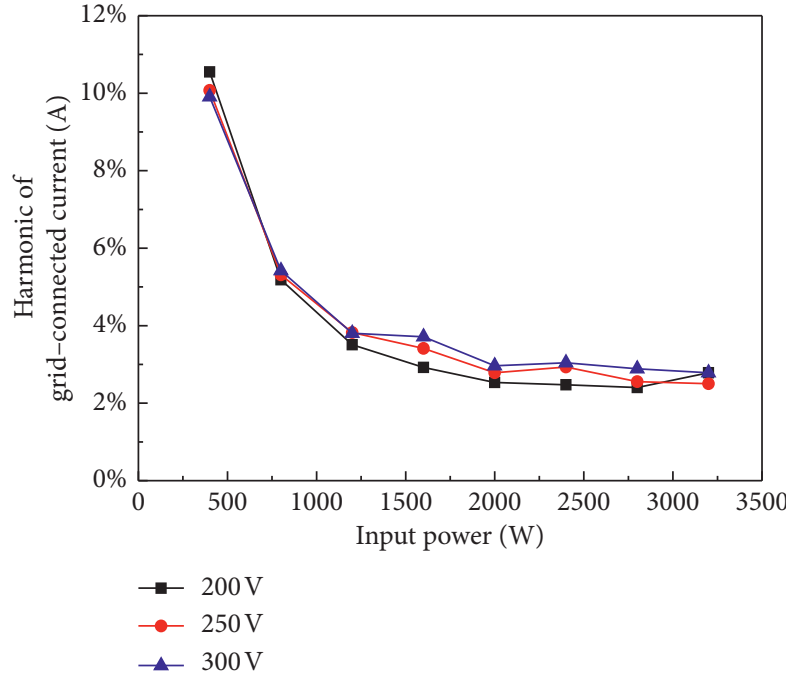

(a)

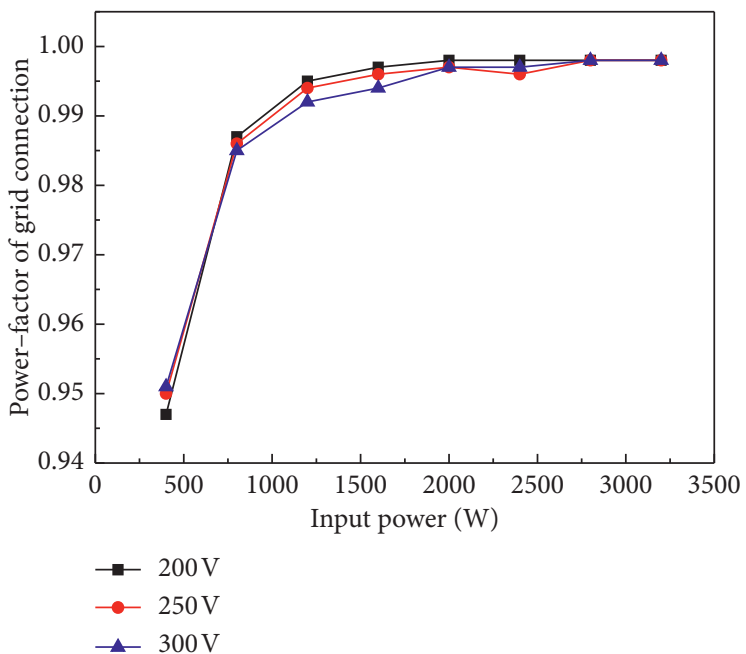

(b)

FIGURE 15: Curve of deadbeat control performance. (a) Curve of harmonics of grid-connected current. (b) Curve of power factor of grid connection. 
of input voltage, the harmonic distortion of current increases, as shown in Figure 15(a). When the input power is $3200 \mathrm{~W}$, the harmonic distortion of the grid current is only about $2.5 \%$, which meets the initial design requirements. The greater the input power of the photovoltaic inverter, the higher the power factor of the grid, the lower the input voltage, and the higher the power factor, as shown in Figure 15(b); the final power factor is up to 0.998, which meets the design requirements of the power factor greater than 0.99 .

\section{Conclusion}

In this paper, an improved control strategy of full-bridge circuit is studied, with the improved Newton interpolation predictive delay compensation algorithm and the online inductance identification and compensation algorithm based on frequency-doubling sampling proposed. Simulation and experimental results show that the proposed control strategy can improve effectively the control accuracy of output current and that they can improve the quality of grid-connected power. When the input power is $3.2 \mathrm{~kW}$, the harmonic for grid current is only $2.5 \%$, and the power factor reaches up to 0.998 . However, interpolation prediction and double frequency inductance detection increase the amount of algorithm, and a lot of work needs to be done to timing optimization in DSP programming.

\section{Data Availability}

The simulation and waveform data used to support the findings of this study are available from the author (Jiaxiang Xue) upon request.

\section{Conflicts of Interest}

The authors declare no conflicts of interest.

\section{Authors' Contributions}

Z.F. and H.X conceptualized the study. Z.F. was responsible for methodology. H.L. and Z.F. performed the experiment. Z.F. and Z.L. wrote the study (original draft preparation). J.X. was responsible for project administration.

\section{Acknowledgments}

This research was funded by the Fujian Natural Science Foundation (2018J01541 and 2018J01503), the Fujian Provincial Education Hall Science and Technology Class A (JA15486), the 2015 Dongguan City to Introduce the Third Batch of Innovative Scientific Research Team Project (2017360004004), the Guangzhou Nansha District Science and Technology Program (2017CX009), the Guangdong Provincial Department of Communications Science and Technology Project (Science and Technology-201702-041), and Longyan City Science and Technology Project (2017LY68).

\section{References}

[1] Z. Tang, "Four PI controller design methods for grid-connected inverter based on LCL output filter," Grid Technology, vol. 37, no. 11, pp. 3268-3275, 2013.

[2] F. M. Ali and V. D. B. Alex, "Investigation of a delay compensated deadbeat current controller for inverters by Z-transform," Electrical Engineering, vol. 100, pp. 2341-2349, 2018.

[3] M. S. Omar, A. El-Deib, A. L. El Shafei et al., "Comparative study between PI and fuzzy-logic controllers for three-phase grid-connected photovoltaic systems," in Proceedings of the Power Systems Conference (MEPCON), 2016 Eighteenth International Middle East, pp. 380-386, IEEE, Cairo, Egypt, 2016.

[4] K. Colak, E. Asa, and D. Czarkowski, "Dual closed loop control of LLC resonant converter for EV battery charger," in Proceedings of the International Conference on Renewable Energy Research \& Applications, Madrid, Spain, 2014.

[5] S. S. Mikhalevich, S. A. Baydali, and F. Manenti, "Development of a tunable method for PID controllers to achieve the desired phase margin," Journal of Process Control, vol. 25, no. 25 , pp. 28-34, 2015.

[6] L. Huber, M. Kumar, and M. M. Jovanovic, "Performance comparison of PI and P compensation in DSP-based averagecurrent-controlled three-phase six-switch boost PFC rectifier," IEEE Transactions on Power Electronics, vol. 30, no. 12, pp. 7123-7137, 2015.

[7] J. F. Stumper, V. Hagenmeyer, S. Kuehl et al., "Deadbeat control for electrical drives: a robust and performant design based on differential flatness," IEEE Transactions on Power Electronics, vol. 30, no. 8, pp. 4585-4596, 2014.

[8] X. X. Hou, M. Qin, J. F. Mao et al., "Two stage single-phase single-phase photovoltaic grid connected inverter input voltage PI+QPR robust controller design," Power Grid Technology, vol. 41, no. 09, pp. 2910-2918, 2017.

[9] N. Ikken, A. Bouknadel, H. ElOmari et al., "Design and implementation of intelligent PI-fuzzy logic control for grid connected inverters," in Proceedings of the Renewable and Sustainable Energy Conference (IRSEC), 2016 International, pp. 1111-1117, IEEE, Marrakech, Morocco, 2016.

[10] K. Basaran and N. S. Cetin, "Designing of a fuzzy controller for grid connected photovoltaic system's converter and comparing with PI controller," in Proceedings of the Renewable Energy Research and Applications (ICRERA), 2016 IEEE International Conference on. IEEE, pp. 102-106, Birmingham, UK, 2016.

[11] M. J. Navardi, J. Milimonfared, and H. A. Talebi, “Torque and flux ripples minimization of permanent magnet synchronous motor by a predictive-based hybrid direct torque control," IEEE Journal of Emerging \& Selected Topics in Power Electronics, vol. 6, no. 99, p. 1, 2018.

[12] A. Benyoucef, K. Kara, A. Chouder, and S. Silvestre, "Prediction-based deadbeat control for grid-connected inverter with L-filter and LCL-filter," Electric Power Components and Systems, vol. 42, no. 12, pp. 1266-1277, 2014.

[13] Y. Atia and M. M. Salem, "Novel deadbeat power control strategy for grid connected systems," Journal of Electrical Systems \& Information Technology, vol. 2, no. 2, Article ID S2314717215000434, 2015.

[14] B. Kouvaritakis, M. Cannon, and D. Muñoz-Carpintero, "Efficient prediction strategies for disturbance compensation in stochastic MPC," International Journal of Systems Science, vol. 44, no. 7, pp. 1344-1353, 2013. 
[15] L. Yang, Y. Chen, A. Luo et al., "A double update PWM method to improve robustness for the deadbeat current controller in three-phase grid-connected system," Journal of Electrical and Computer Engineering, vol. 2018, Article ID 2972379, 13 pages, 2018.

[16] H. Mohamed, S. Raafat, and S. Mostafa, "A hybrid partial feedback linearization and deadbeat control scheme for a nonlinear gantry crane," Journal of the Franklin Institute, vol. 355, no. 14, pp. 6286-6299, 2018.

[17] H. Mohamed, S. Raafat, and S. Mostafa, "Experimental verification of a hybrid control scheme with chaotic whale optimization algorithm for nonlinear gantry crane a comparative study," ISA Transactions, vol. 8, p. 28, 2019.

[18] W. Ping, X. B. Yu, G. Fei et al., "An improved deadbeat control methodfor single-phase PWM rectifiers in charging system for EVs," IEEE Transactions on Vehicular Technology, vol. 35, pp. 9672-9681, 2015.

[19] Z. Zheng, T. Zhang, and J. Xue, "Application of fuzzy control in a photovoltaic grid-connected inverter," Journal of Electrical and Computer Engineering, vol. 2018, Article ID 3806372, 10 pages, 2018.

[20] S. Buso, T. Caldognetto, and D. I. Brandao, "Dead-beat current controller for voltage-source converters with improved large-signal response," IEEE Transactions on Industry Applications, vol. 52, pp. 1588-1596, 2016.

[21] C. Schmuck, F. Woittennek, A. Gensior, and J. Rudolph, "Feed-forward control of an HVDC power transmission network," IEEE Transactions on Control Systems Technology, vol. 22, no. 2, pp. 597-606, 2014.

[22] K. Nishida, T. Ahmed, and M. Nakaoka, "Cost-effective deadbeat current control for wind-energy inverter application with \$LCL\$ filter," IEEE Transactions on Industry Applications, vol. 50, no. 2, pp. 1185-1197, 2014.

[23] S.-C. Tan, C. K. Lee, and S. Y. Hui, "General steady-state analysis and control principle of electric springs with active and reactive power compensations," IEEE Transactions on Power Electronics, vol. 28, no. 8, pp. 3958-3969, 2013.

[24] A. Aswani, S. S. Gonzalez, and C. Tomlin, "Provably safe and robust learning-based model predictive control," Automatica, vol. 49, no. 5, pp. 1216-1226, 2013.

[25] M. Rivera, J. Rodriguez, J. R. Espinoza, and H. Abu-Rub, "Instantaneous reactive power minimization and current control for an indirect matrix converter under a distorted AC supply," IEEE Transactions on Industrial Informatics, vol. 8, no. 3, pp. 482-490, 2012.

[26] X. U. Rong, Y. U. Yong, N. Y. Yan et al., "Dead-beat control of $\mathrm{H}$-bridge cascaded STATCOM based on discrete state observer," Automation of Electric Power Systems, vol. 38, no. 21, pp. 58-65, 2014.

[27] A. Bouafia, J.-P. Gaubert, and F. Krim, "Design and implementation of predictive current control of three-phase PWM rectifier using space-vector modulation (SVM)," Energy Conversion and Management, vol. 51, no. 12, pp. 2473-2481, 2010.

[28] S. Shimmyo and K. Ohnishi, "Disturbance observer for deadtime compensation with variable gain and its stability analysis based on popov criterion," in Proceedings of the Conference of the IEEE Industrial Electronics Society, Yokohama, Japan, November 2016.

[29] M. Z. Daud, A. Mohamed, and M. A. Hannan, “An improved control method of battery energy storage system for hourly dispatch of photovoltaic power sources," Energy Conversion and Management, vol. 73, no. 5, pp. 256-270, 2013.
[30] T. Yokoyama and T. Saigusa, "Multirate deadbeat control for $100 \mathrm{kHz}$ single phase utility interactive inverter with FPGA based hardware controller," IEEJ Transactions on Industry Applications, vol. 131, no. 131, pp. 1042-1048, 2011.

[31] R. Keshri, S. G. Kadwane, J. M. Kumbhare et al., "Ripple free deadbeat control of DC-DC buck converter for distributed generators," in Proceedings of the Conference of the IEEE Industrial Electronics Society, Florence, Italy, 2016.

[32] S. J. Ovaska, "Newton-type predictors-a signal processing oriented viewpoint," Signal Processing, vol. 25, no. 2, pp. 251-257, 1991.

[33] Y. Daili, J. P. Gaubert, L. Rahmani et al., "An improved voltage control scheme based on deadbeat-repetitive techniques of a single distributed generation unit in island mode," in Proceedings of the Conference of the IEEE Industrial Electronics Society, Vienna, Austria, November 2014.

[34] T. Messo, J. Jokipii, and T. Suntio, "Effect of conventional grid-voltage feedforward on the output impedance of a threephase photovoltaic inverter," in Proceedings of the 2014 International Power Electronics Conference (IPEC-Hiroshima 2014-ECCE ASIA), Hiroshima, Japan, 2014.

[35] E. I. Aliyu, S. D. Huang, W. Liao, and A. M. Saliu, "MRAS based speed sensor-less vector controlled induction motor using modified adaptive mechanism," Sensors and Transducers, vol. 155, no. 8, pp. 80-85, 2013.

[36] E. Isen and A. F. Bakan, "10 kW grid-connected three-phase inverter system: control, simulation and experimental results," in Proceedings of the IEEE International Symposium on Power Electronics for Distributed Generation Systems, Aalborg, Denmark, June 2012.

[37] M.-C. Wong, Y.-Z. Yang, C.-S. Lam et al., "Self-reconfiguration property of a mixed signal controller for improving power quality compensation during light loading," IEEE Transactions on Power Electronics, vol. 30, no. 10, pp. 59385951, 2015.

[38] Y. Chen, T. Ji, M. Li, Q. Wu, and X. Wang, "Power system harmonic estimation based on park transform," Journal of Electrical Engineering and Technology, vol. 11, no. 3, pp. 560-574, 2016. 


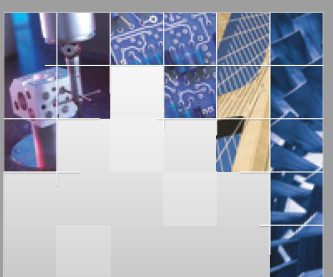

\section{Enfincering}
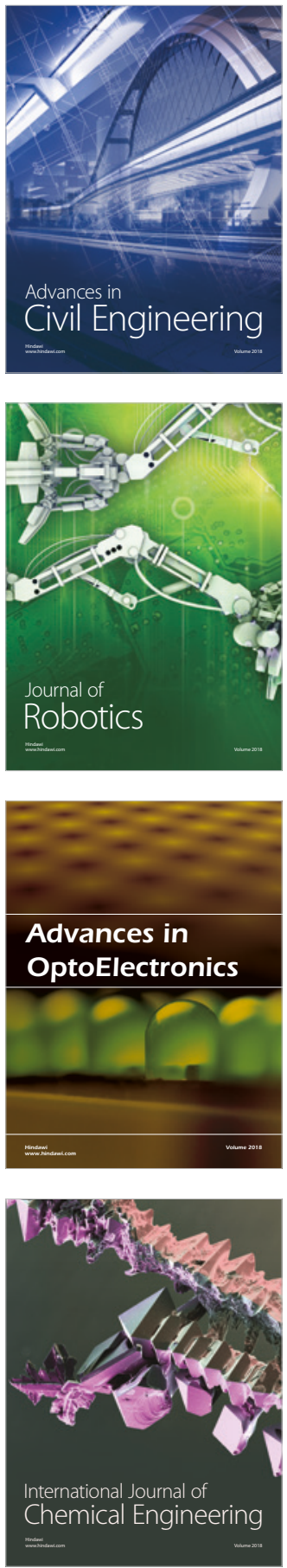

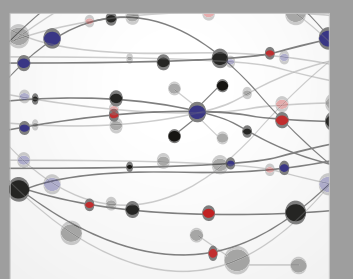

\section{Rotating \\ Machinery}

The Scientific World Journal

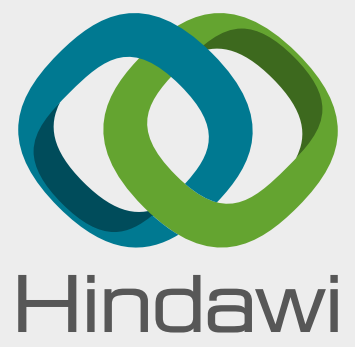

Submit your manuscripts at

www.hindawi.com
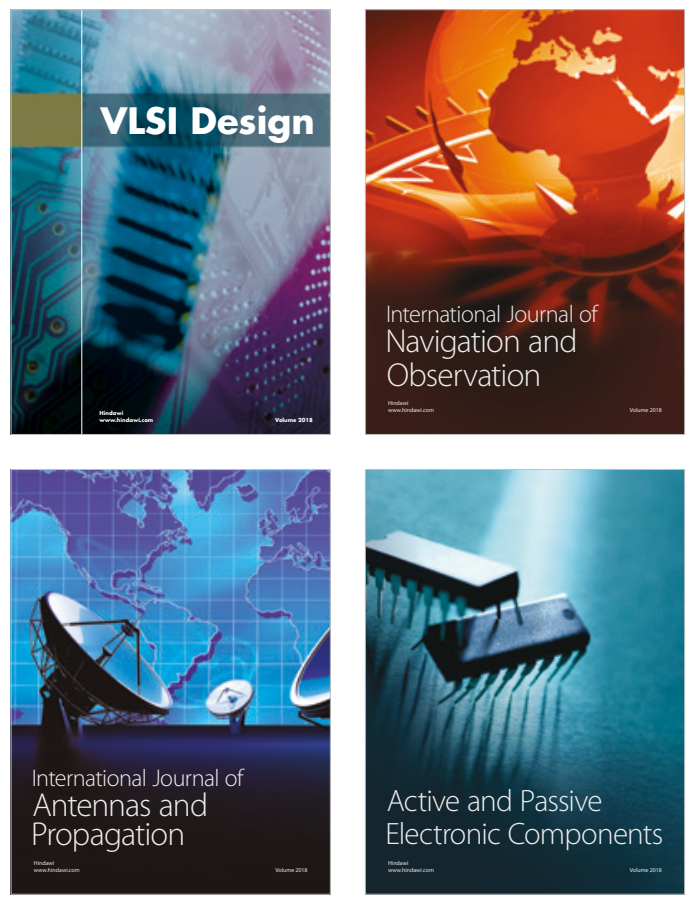
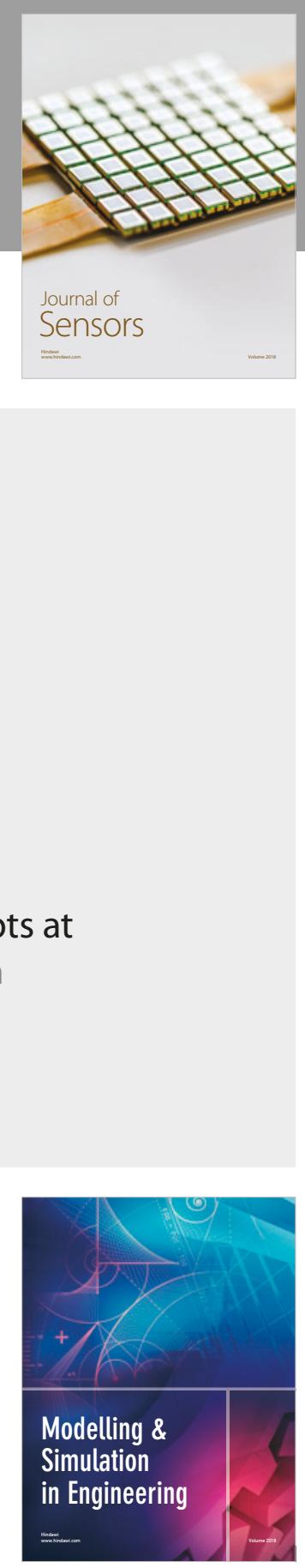

\section{Advances \\ Multimedia}
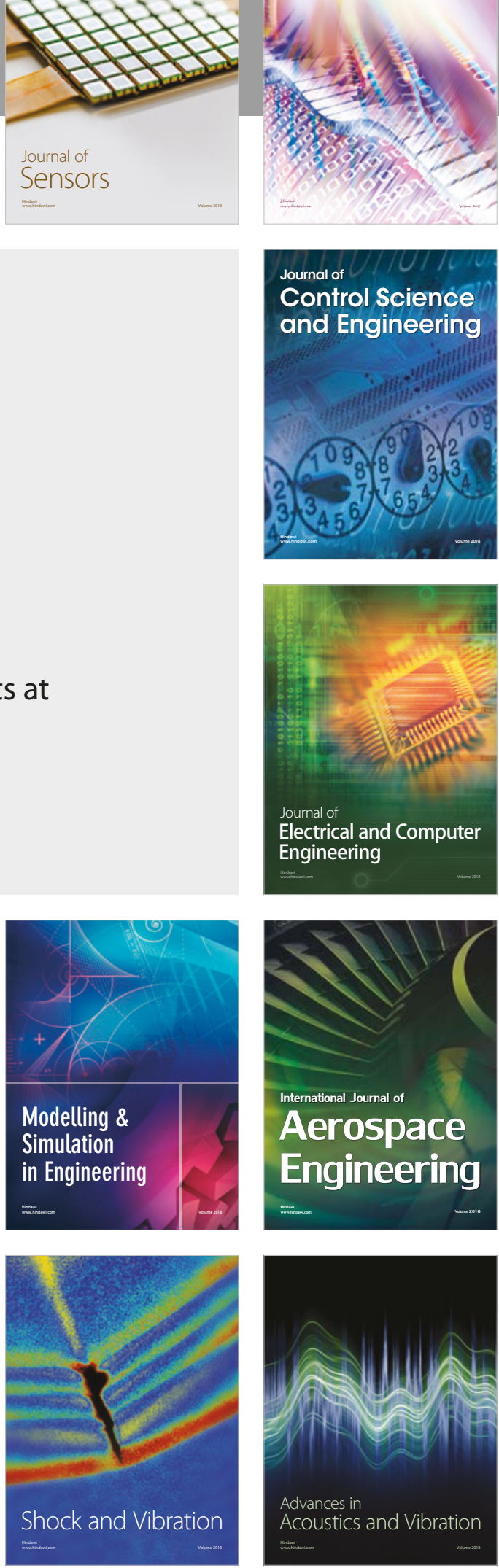